\title{
Pennsylvania policymakers' knowledge, attitudes and likelihood for action regarding waterpipe tobacco smoking and electronic nicotine delivery systems
}

\author{
Beth L. Hoffman', Megan C. Tulikangas' ${ }^{1}$, A. Everette James' ${ }^{1}$ Ariel Shensa', Jason B. Colditz', Jaime E. Sidani', Brian A. Primack'
}

\begin{abstract}
INTRODUCTION Use of waterpipe tobacco smoking (WTS, or hookah smoking) and electronic nicotine delivery systems (ENDS, such as e-cigarettes) is rapidly increasing. However, legislatures have been slow to update policy measures related to them. Therefore, we aimed to assess knowledge, attitudes and likelihood to take future action regarding WTS and ENDS among Pennsylvania legislators.

Methods We approached all Standing Members of key Pennsylvania House and Senate health and welfare committees to complete a survey about substances of abuse, including WTS and ENDS. Closed-ended knowledge, attitude and action items used a 100-point scale. Responses to open-ended items were assessed using thematic analysis by three independently working researchers.

RESULTS We received responses from 13 of 27 eligible policymakers (48\%). Participants answered a mean of only $27 \%(\mathrm{SD}=20 \%)$ of knowledge items correctly. When asked to rank by priority eight issues in substance abuse, WTS ranked eighth (least urgent) and ENDS ranked fifth. Participants reported low likelihood to introduce legislation on WTS $($ mean $=29$, median $=25)$ and/or ENDS (mean=28, median=10). Thematic analysis revealed that participants readily acknowledged lack of understanding of WTS and ENDS, and were eager for additional information.

CONCLUSIONS Policymakers exhibit a lack of knowledge concerning newer forms of tobacco and nicotine delivery systems and consider them to be relatively low legislative priorities. However, respondents expressed a desire for more information, suggesting the potential for public health entities to promote effective policy development via improved dissemination of information.
\end{abstract}

\section{AFFILIATION \\ 1 University of Pittsburgh, Pittsburgh, United States}

CORRESPONDENCE TO

Brian A. Primack. University of Pittsburgh, 230 McKee Place,

Suite 600, 15213 Pittsburgh, United States.

Email: bprimack@pitt.edu

\section{KEYWORDS}

legislation, policy, electronic cigarettes, new tobacco products, nicotine or derivatives

Received: 11 October 2017 Revised: 28 March 2018 Accepted: 29 March 2018

\section{INTRODUCTION}

Use of new and emerging tobacco and nicotine products, such as waterpipe tobacco smoking (WTS, or hookah smoking) and electronic nicotine delivery systems (ENDS, or 'e-cigarettes'), has been steadily increasing in the USA, especially among adolescents and young adults ${ }^{1-4}$. A nationwide examination by the US Centers for Disease Control and Prevention found that, among high school students in 2014, the prevalence of current WTS and ENDS use was $9.4 \%$ and $13.4 \%$, respectively, both higher than the prevalence of current cigarette use $(9.2 \%)^{5}$.

The FDA Center for Tobacco Products has been given regulatory authority over these emerging forms of tobacco and nicotine in the US, but policymaking responsibility for regulating the sale and use of these products falls primarily to State and Local officials ${ }^{6}$. Pennsylvania is a valuable State in which to examine tobacco policies addressing WTS and ENDS because it is politically diverse, with a range of Democratic and Republican elected officials representing urban, suburban and rural communities. There 
are also well-established tobacco control advocacy groups and tobacco manufacturers/processors that may influence the development of legislation. Furthermore, according to the National Conference of State Legislatures, as of May 2016 Pennsylvania was the only State that had not enacted legislation prohibiting the sale of ENDS to minors ${ }^{7}$. Therefore, the purpose of this study was to survey members of the Pennsylvania legislature to assess knowledge of, attitudes toward, and likelihood to support future regulations pertaining to WTS and ENDS.

\section{METHODS}

\section{Survey participants}

Based on consultation with policy experts and a search of the committees of origin for bills that contained the words 'electronic cigarette' or 'waterpipe tobacco', we determined that members of the Pennsylvania House Health and Senate Health and Welfare committees would be most likely to consider tobacco policy bills. Thus, we selected members of these committees as our survey population. After initially mailing 36 surveys to committee members, we received statements from five individuals that they do not participate in surveys. In addition, one respondent resigned and three could not be reached for followup because they lacked email and fax capabilities. Our final survey population was 27 individuals. This study was approved by the University of Pittsburgh Institutional Review Board.

\section{Survey design}

We developed a comprehensive survey based on conceptual understandings from our policy document reviews ${ }^{8}$, practical insights from preliminary interview feedback and previous policy studies ${ }^{9,10}$. It included 51 closed-ended and four open-ended questions. Except for one question that asked respondents to rank substances according to priority for legislative action, all closed-ended questions utilized a visual analogue scale. Visual analogue scales are continuous measurement devices that are considered reliable and valid ${ }^{11}$. For each set of questions, 0 represented strongly negative answers (i.e. 'strongly disagree') on the one hand and 100 represented strongly positive answers (i.e. 'strongly agree') on the other.

First, we asked participants to rate their familiarity with WTS and ENDS devices and current policy regulations. To assess knowledge, we asked 14 true/ false items using the visual analogue scale described above, with 0 as 'definitely false' and 100 as 'definitely true'. We also asked participants to answer two open-ended questions related to knowledge. Second, we asked participants to rank the importance of policy related to ENDS and WTS compared to policy concerning other addictive substances (eight in total), and to rate their level of agreement with five statements such as 'Hookah smoking is a public health problem'. Third, we asked participants 15 questions about how likely they would be to take certain actions relating to WTS or ENDS in the next six months. We also asked participants to answer two open-ended questions about regulation.

\section{Survey dissemination}

Recognizing that this is a notoriously difficult population to assess ${ }^{12-14}$, we conducted multiple rounds of dissemination of the survey via mail, email, fax and phone. Experts with significant ties to the legislature also personally reached out to members of these committees.

\section{Analysis}

Researchers entered the data from each survey response under each participant's unique ID number. The printed visual analogue scale was 10 centimeters, so to determine the numeric value of each answer a researcher measured where the respondent's mark fell on the line to the nearest half-centimeter. During the recruitment phase, several policy changes occurred that affected the answers to certain questions; we eliminated these questions during our analysis.

Data were analyzed using Stata $13^{15}$. We calculated basic descriptive statistics for all closed-ended questions. For the true/false items, we defined a score between 0-10 as correct for the false items, and $90-100$ as correct for the true items. To facilitate analysis, we converted these results to 'mean correctness' and 'median correctness'. To calculate mean correctness, we used the actual mean for items that were true, and 100 minus the mean for items that were false. We used the same technique to calculate median correctness. Therefore, the closer the mean or median was to 100 , the greater number of respondents answered the item correctly. 
For the open-ended questions, two researchers conducted a qualitative analysis using a groundedtheory approach. After three rounds of analysis and subsequent discussion, the researchers met with a supervising researcher to synthesize themes from the open-ended questions with the data from the closedended questions.

\section{RESULTS}

We received 13 completed surveys (48\%). This response rate is considered excellent when conducting research with policymakers ${ }^{12-14}$. Two individuals were lost to follow-up, as they logged onto the online platform but did not complete the survey. Response rates were the same for both chambers $(36 \%)$. Of the 13 respondents, 7 (54\%) were female and 8 (62\%) were Republican.

\section{Survey analysis}

On a scale from 0 (not at all familiar) to 100 (very familiar), participants rated their overall familiarity with WTS as 28 (Standard Deviation [SD]=15). This number was slightly higher for ENDS, with a mean of 50 ( $\mathrm{SD}=13)$. For both WTS and ENDS, policymakers rated their familiarity of current public health data and regulatory standards lower than their familiarity with how these products are used.

Participants answered a mean of only $27 \%$ $(\mathrm{SD}=20 \%)$ of knowledge items correctly. Mean correctness was not significantly above or below 50 for $12(86 \%)$ items, indicating that participants were generally unsure about the correct answer. For the items specific to WTS, participants answered a mean of $24 \%$ ( $\mathrm{SD}=15 \%)$ correctly. Participants were slightly more knowledgeable about ENDS, answering a mean of $30 \%(\mathrm{SD}=24 \%)$ of the items correctly. Qualitative analysis of open-ended items revealed the primary theme that policymakers felt that they had insufficient knowledge to make effective policy on both substances, although consistent with the quantitative results, participants felt slightly more informed about ENDS. The majority of participants requested general information about both products (Table 1).

\section{Table 1. Verbatim responses to open-ended questions}

\begin{tabular}{|c|c|}
\hline Question & Quotation \\
\hline \multirow{12}{*}{$\begin{array}{l}\text { Do you feel that you have } \\
\text { enough knowledge of hookah } \\
\text { smoking to make effective } \\
\text { policy? If not, what facts would } \\
\text { be the most helpful? }\end{array}$} & No-please provide. \\
\hline & No-background information. \\
\hline & $\begin{array}{l}\text { No-it's really not discussed and I have minimal knowledge of it. I would like to [know] nicotine content } \\
\text { and cancer risk. }\end{array}$ \\
\hline & I do not have enough knowledge and would appreciate knowing answers to above questions. \\
\hline & I do not know what it is-Hookah smoking 101 would be helpful. \\
\hline & Comparison information to cigarettes. \\
\hline & Very unfamiliar-didn't know their use is even statistically significant. \\
\hline & No. Very unfamiliar with hookah smoking. \\
\hline & No. Information regarding general usage and effects would be helpful. \\
\hline & No. Any empirical data validated by legitimate scientific research. \\
\hline & Basic facts. \\
\hline & Probably not-\% of use, \% of use among minors. \\
\hline \multirow{12}{*}{$\begin{array}{l}\text { Do you feel that you have } \\
\text { enough knowledge of electronic } \\
\text { cigarettes to make effective } \\
\text { policy? If not, what facts would } \\
\text { be the most helpful? }\end{array}$} & Yes-please provide more. \\
\hline & Some-background information and facts. \\
\hline & Yes. \\
\hline & Not enough information. Any and all information useful. \\
\hline & Chemical makeup of 'vapor' emitted (actually not vapor in my mind). \\
\hline & Comparison information to cigarettes. \\
\hline & I know a lot more about e-cigarettes although I am not an expert. \\
\hline & Yes. More information-not necessarily more research. \\
\hline & Yes \\
\hline & No. Any empirical data validated by legitimate scientific research. \\
\hline & Basic facts. \\
\hline & Yes. \\
\hline
\end{tabular}


Table 1. Continued

\begin{tabular}{|c|c|}
\hline Question & Quotation \\
\hline \multirow{12}{*}{$\begin{array}{l}\text { What do you think is the } \\
\text { greatest barrier to regulation } \\
\text { (e.g. particular interest groups or } \\
\text { individuals, logistic challenges) } \\
\text { of hookah smoking? }\end{array}$} & Lack of knowledge-facts. \\
\hline & Not enough knowledge of hookah smoking to reply. \\
\hline & Apathy. \\
\hline & Particular interest groups. Lack of information on health risks. \\
\hline & No idea. \\
\hline & $\begin{array}{l}\text { Lack of knowledge of hookah use. Would probably be easier to regulate [because] of cultural } \\
\text { implications (e.g. often seen as done by foreign populations, and hence, 'un-American'). }\end{array}$ \\
\hline & Information on how they work-how much they are use-and their certified health effects. \\
\hline & Middle Eastern Culture would be opposed. \\
\hline & Interest groups and individuals. \\
\hline & Lack of information regarding hookah smoking. \\
\hline & $?$ \\
\hline & Non-interest. \\
\hline \multirow{12}{*}{$\begin{array}{l}\text { What do you think is the } \\
\text { greatest barrier to regulation } \\
\text { (e.g. particular interest groups or } \\
\text { individuals, logistic challenges) } \\
\text { of e-cigarettes? }\end{array}$} & See above [Lack of knowledge-facts]. \\
\hline & Distain [sic] for any governmental regulation. \\
\hline & Efforts not well organized. \\
\hline & Particular interest groups. Lack of information on health risks. \\
\hline & Constituents who claim they use e-cigarettes as a tool for smoking cessation. \\
\hline & Interest groups wield tremendous influence, prevent movement of legislation. \\
\hline & Not necessary. \\
\hline & Privately owned smoke shops. \\
\hline & Interest groups and individuals. \\
\hline & See above [Lack of information]. \\
\hline & An advocate. \\
\hline & Still very new, from a policy perspective. \\
\hline \multirow{4}{*}{$\begin{array}{l}\text { Do you have any additional } \\
\text { comments? }\end{array}$} & Thank you! \\
\hline & No. \\
\hline & Not certain we need to over-regulate these issues. \\
\hline & No. \\
\hline
\end{tabular}

For legislative priority of substance abuse, WTS was ranked eighth (least urgent), and ENDS was ranked fifth. Participants were least likely to agree that WTS is a public health problem, with a mean of 55 $(\mathrm{SD}=28)$. Participants had slightly more agreement that ENDS are a public health problem, with a mean of $65(\mathrm{SD}=28)$. In comparison, agreement that traditional cigarettes are a public health problem had a mean of $72(\mathrm{SD}=20)$, and prescription opioid painkillers had a mean of $92(\mathrm{SD}=15)$.

On a scale from 0 (not at all likely) to 100 (very likely), the median likelihood to introduce legislation aimed at curbing rates of WTS and ENDS use was
25 and 10, respectively (Figure 1). Democrats were more likely to favor raising taxes on WTS products (median $=90$, mean $=84$ ) and ENDS (median $=90$, mean $=84$ ) than Republicans (WTS: median $=55$, mean $=52$; ENDS: median=58, mean=56). Democrats were also more likely to support amending the Clean Indoor Air Act to include ENDS (median $=90$, mean $=86$ ) than Republicans (median $=50$, mean $=51$ ). When asked about barriers to regulation of WTS in an open-ended question, lack of knowledge again emerged as a theme, with five participants ( $42 \%)$ identifying it as the greatest barrier (Table 1). For ENDS, legislators mentioned 


\section{Figure 1. Respondents median likelihood to take future action concerning WTS and ENDS}

\section{Likelihood to Take Future Action Concering WTS and ENDS}

Prohibiting the use of electronic cigarettes on school grounds Raising taxes on electronic cigarettes or liquid nicotine products Raising taxes on hookah tobacco Amending the PA Clean Indoor Air Act to specifically address electronic cigarette Request information about electronic cigarettes Request information about hookah tobacco Regulating the content of liquid nicotine Support legislation aimed at decreasing rates of electronic cigarette use Regulating the content of hookah tobacco Limiting flavorings in liquid nicotine Amending the PA Clean Indoor Air Act to specifically address hookah smoking Limiting flavorings in hookah tobacco Support legislation aimed at decreasing rates of hookah tobacco smoking Introduce legislation aimed at decreasing rates of hookah tobacco smoking Introduce legislation aimed at decreasing rates of electronic cigarette use

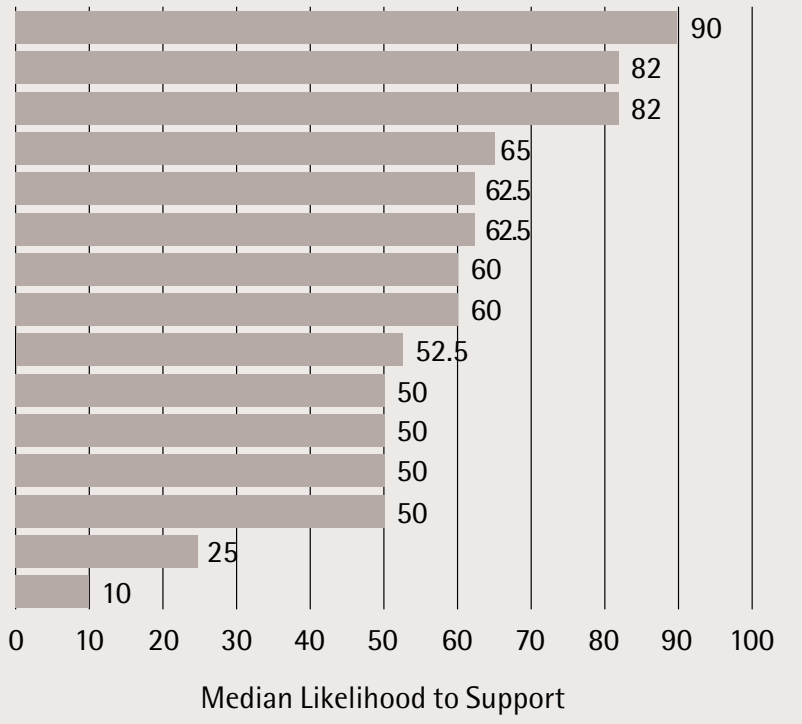

the role of interest groups, such as privately-owned smoke shops most frequently ( $42 \%)$, followed by lack of information ( $25 \%$ : Table 1$)$.

\section{DISCUSSION}

Despite the fact that tobacco use remains a leading cause of preventable death in Pennsylvania, this survey suggests that policymakers lack knowledge concerning newer forms of nicotine and tobacco products and consider them to be relatively low legislative priorities. Although our sample population was small and limited to Members of one State's legislature, this study provides several findings that may be useful for public health practitioners and others engaged in public policy.

State policymakers in our study did not view the regulation of WTS and ENDS as a high priority when compared to other substances of abuse. This may be in part because other substances (such as opioids) have recently garnered substantial news media attention, making legislators more likely to act on them ${ }^{16}$. Moreover, we found that lack of knowledge of WTS and ENDS may contribute to legislative inaction. Thus, there is potential for public health entities to promote policymakers' development of legislation via improved dissemination of information and increased exposure to effective educational material ${ }^{17}$.

In 1976, the Pennsylvania House of Representatives created a Legislative Office Research Liaison (LORL) to organize policymaking research support from the State's public, State-related, and private universities. Over the years, LORL responded to thousands of legislative inquires, hosted hundreds of visiting scholars and published reports and policy research papers to support evidence-based policymaking in the Pennsylvania Legislature ${ }^{18}$. However, persistent State budget deficits led to the withdrawal of funding and closure of LORL in $2009^{19}$.

New partnerships are needed to ensure that policymakers are informed of existing evidence in order to make informed policy decisions. These partnerships could be forged via traditional means (e.g. face-to-face meetings), or novel mechanisms such as online portals. One example of the latter is Web CIPHER, an Australian online portal that has demonstrated effectiveness in connecting policymakers with research updates and other tools to help them better access and engage with research ${ }^{20}$. Since policymakers in our study expressed a desire for more information about WTS and ENDS, such a portal might represent a novel way to disseminate this information to them in a timely fashion.

\section{Limitations}

Despite a complex protocol that involved multiple rounds of mailing, emailing and faxing the survey, 
we found it difficult to recruit policymakers to take part in our survey. Although our final response rate of $48 \%$ was higher than previous similar studies ${ }^{12-14}$, lack of enthusiasm for participation in survey research by policymakers remains an obstacle to conducting this research. Because of our small sample size, we were unable to conduct further analysis, such as stratifying according to party affiliation, which may have provided useful insight. In addition, we had to exclude some items in the initial survey due to the changing of laws and regulations that occurred while we were disseminating the survey. Finally, interpretation of the answers to the open-ended questions could be subjective, although we aimed to minimize subjectivity through multiple rounds of analysis and the use of a supervising researcher.

\section{CONCLUSIONS}

This study suggests that: 1) lack of knowledge of WTS and ENDS may contribute to legislative inaction from policymakers, and 2) policymakers do not view the regulation of WTS and ENDS as a high priority when compared to other substances of abuse. Improved lines of communication between public health experts and policy makers may be crucial to the development of policies that adapt to changing patterns of tobacco and nicotine use.

\section{REFERENCES}

1. Wills TA, Knight R, Williams R, Pagano I, Sargent JD. Risk factors for exclusive e-cigarette use and dual e-cigarette use and tobacco use in adolescents. Pediatrics. 2015;135(1):e43-e51. doi:10.1542/peds.2014-0760

2. Walton KM, Abrams DB, Bailey WD, et al. NIH electronic cigarette workshop: developing a research agenda. Nicotine Tob Res. 2015;17(2):259-269. doi:10.1093/ntr/ntu214

3. Dugas EN, O’Loughlin EK, Low NC, Wellman RJ, O'Loughlin JL. Sustained waterpipe use among young adults. Nicotine Tob Res. 2014;16(6):709-716. doi:10.1093/ntr/ntt215

4. Primack BA, Freedman-Doan P, Sidani JE, et al. Sustained waterpipe tobacco smoking and trends over time. Am J Prev Med. 2015;49(6):859-867. doi:10.1016/j.amepre.2015.06.030

5. Arrazola RA, Singh T, Corey CG, et al. Tobacco Use among Middle and High School Students - United States, 2011-2014. Vol 64. Atlanta; 2015.

6. Administration USF and D. Section 916 of the Federal
Food, Drug, and Cosmetic Act - Preservation of State and Local Authority. http://www.fda.gov/TobaccoProducts/ Labeling/RulesRegulationsGuidance/ucm261893.htm. Published 2015. Accessed January 31, 2018.

7. Alternative nicotine products: electronic cigarettes. National Conference of State Legislatures. http://www. ncsl.org/research/health/alternative-nicotine-productse-cigarettes.aspx. Published May 2016. Accessed January 31, 2018.

8. Colditz JB, Ton JN, James AE, Primack BA. Toward effective water pipe tobacco control policy in the United States: synthesis of federal, state, and local policy texts. Am J Heal Promot. 2017;31(4):302-309. doi:10.4278/ajhp.150218-QUAL-736

9. European Association for the Study of Obesity. Policymaker Survey 2014 - EASO.; 2014. http://easo. org/policymakersurvey/. Accessed, October 2017

10. Rouch G, Thomson G, Wilson N, et al. Public, private and personal: qualitative research on policymakers' opinions on smokefree interventions to protect children in "private" spaces. BMC Public Health. 2010;10:797. doi:10.1186/1471-2458-10-797

11. Reips U-D, Funke F. Interval-level measurement with visual analogue scales in Internet-based research: VAS Generator. Behav Res Methods. 2008;40(3):699-704. doi:10.3758/BRM.40.3.699

12. Welch PJ, Dake JA, Price JH, Thompson AJ, Ubokudom SE. State legislators' support for evidence-based obesity reduction policies. Prev Med (Baltim). 2012;55(5):427239. doi:10.1016/j.ypmed.2012.09.008

13. Payton E, Thompson A, Price JH, Sheu JJ, Dake JA. African American legislators' perceptions of firearm violence prevention legislation. J Community Health. 2015;40(3):439-447. doi:10.1007/s10900-014-9954-3

14. York NL, Pritsos CA, Gutierrez AP. Legislators' beliefs on tobacco control policies in Nevada. J Community Health. 2012;37(1):89-95. doi:10.1007/s10900-011-9421-3

15. StataCorp. Stata Statistical Software: Version 14. 2015.

16. Sorian R, Baugh T. Power of information: closing the gap between research and policy. Health Aff. 2002;21(2):264-273. doi:10.1377/hlthaff.21.2.264

17. Dodson EA, Stamatakis KA, Chalifour S, Haire-Joshu D, McBride T, Brownson RC. State legislators' work on public health-related issues: what influences priorities? J Public Heal Manag Pract. 2013;19(1):25-29. doi:10.1097/PHH.0b013e318246475c

18. Jensen GWR. Legislative Office for Research Liaison. http://intergovernmental.pasenategop.com/ files/2014/03/lorl-background.pdf. Published 2011. Accessed January 31, 2018.

19. Legislative office of research liaison records, 1983-2009. Pennsylvania House of Representatives archives. http:// pahousearchives.org $/ ? \mathrm{p}=$ creators $/$ creator $\& \mathrm{id}=68$. Accessed January 17, 2017.

20. Makkar SR, Howe M, Williamson A, et al. Impact of 
tailored blogs and content on usage of Web CIPHER an online platform to help policymakers better engage with evidence from research. Heal Res Policy Syst. 2016;14(1):85. doi:10.1186/s12961-016-0157-5

ACKNOWLEDGEMENTS

We would like to thank Michelle Woods for editorial assistance.

CONFLICTS OF INTEREST

Dr. Brian A. Primack, Dr. Jaime Sidani, and Jason B. Colditz report grants from National Cancer Institute, during the conduct of the study. The rest of the authors have completed and submitted an ICMJE form for disclosure of potential conflicts of interest. The authors declare that they have no competing interests, financial or otherwise, related to the current work.

FUNDING

The research in the manuscript was funded by the National Cancer Institute (R21-CA185767).

PROVENANCE AND PEER

REVIEW

Not commissioned;

externally peer reviewed 